\title{
Estrutura e composição do estrato herbáceo em um remanescente de Floresta Semidecidual Submontana no Nordeste do Brasil
}

\author{
Jéssica Lira Viana* \& Maria Regina de Vasconcellos Barbosa \\ Centro de Ciências Exatas e da Natureza, Departamento de Sistemática e Ecologia, Universidade Federal da \\ Paraíba - Campus I, João Pessoa, Paraíba, Brasil.
}

\begin{abstract}
Resumo - A vegetação da Floresta Estacional Semidecidual Submontana da Reserva Particular do Patrimônio Natural Fazenda Pedra D’Anta, em Pernambuco, Brasil, foi amostrada com objetivo de: 1- realizar o inventário das ervas terrestres; 2- caracterizar a estrutura da sinúsia herbácea; 3- caracterizar a distribuição geográfica das ervas terrestres; e 4- caracterizar as ervas heliófitas e ciófitas. Foram realizadas caminhadas aleatórias para o levantamento geral das espécies e utilizadas 20 transecções para amostragem da estrutura em 50 parcelas de $1 \mathrm{~m}^{2}$. As frequências e densidades foram calculadas, sendo a diversidade mensurada pelo indicador de riqueza específica $(S)$ e o índice de Shannon $\left(H^{\prime}\right)$. Foram coletadas 107 espécies, representando 75 gêneros e 39 famílias, sendo 25 dessas espécies incluídas no levantamento fitossociológico. Poaceae foi a família com maior número de espécies, tanto no levantamento florístico quanto no fitossociológico. As espécies Parodiolyra micrantha e Oplismenus hirtellus foram as mais frequentes e abundantes. A diversidade específica ( $\left.H^{\prime}\right)$ foi 2,85 nats. O estrato herbáceo mostrou-se rico, apresentando uma composição formada em sua maioria por espécies de ampla distribuição, prevalecendo espécies hemicriptofíticas. Apesar da área estudada apresentar paisagem fragmentada e ocorrência de muitas espécies ruderais, ela representa um refúgio para espécies raras como Psilochilus modestus e Streptochaeta spicata.
\end{abstract}

Palavras-chave adicionais: fitossociologia, floresta tropical, florística, herbáceas terrestres.

\begin{abstract}
Structure and composition of the herb layer in a submontane Atlantic forest remnant in Northeastern Brazil) - The vegetation of a Submontane Semidecidual Seasonal Forest in the Private Natural Heritage Reserve Pedra D'Anta Farm, in Pernambuco State, Brazil, was sampled with the following objectives: 1- to inventory the terrestrial herbs; 2- to characterize the structure of the herbaceous synusiae; 3- to characterize the geographic distribution of terrestrial herbs; and 4- to characterize the heliophyte and sciophyte herbs. Arbitrary walks were performed for a general survey of species, and 20 transects were used to sample the structure in 50 plots of $1 \mathrm{~m}^{2}$ each. Frequencies and densities were calculated, with diversity measured by the indicator of specific richness $(S)$ and the Shannon index $\left(H^{\prime}\right)$. A total of 107 species in 75 genera and 39 families were collected, with 25 of these species included in the phytosociological study. Poaceae was the family with the highest number of species in both floristic and phytosociological studies. The species Parodiolyra micrantha and Oplismenus hirtellus were the most frequent and abundant. Species diversity $\left(H^{\prime}\right)$ was 2.85 nats. The herbaceous layer was found to be rich, having a composition consisting mostly of widely dispersed species, with a prevalence of herbal hemicryptophytes. Although the study area presents a fragmented landscape and occurrence of many ruderal species, it represents a refuge for rare species like Psilochilus modestus and Streptochaeta spicata. Additional key words: floristic, phytosociology, terrestrial herbs, tropical forest.
\end{abstract}

Estudos sobre a estratificação em florestas normalmente levam em conta as diferentes cotas verticais em que se dispõem as plantas. Cada cota, também chamada de estrato, é composta por subconjuntos populacionais de indivíduos com formas de vida ecologicamente homogêneas (Veloso et al. 1991). O estrato de plantas lenhosas foi o foco principal dos estudos fitossociológicos em florestas tropicais durante muitos anos (Gentry 1988; Cestaro et al. 1986), e só mais recentemente começaram a surgir estudos sobre o estrato herbáceo em ambientes florestais (Costa 2004; Palma et al. 2008; CitadiniZanette et al. 2011).

Pesquisas com a sinúsia herbácea em florestas (Cestaro et al. 1986; Dorneles \& Negrelle 1999; Müller \& Waechter 2001; Costa 2004; Soares Jr et al. 2008; Lima \& Gandolfi 2009) são escassas, principalmente pela dificuldade de se estudar conjuntamente os

\footnotetext{
*Autora para correspondência: lira.phb@gmail.com

Editor responsável: Abel A. Conceição

Submetido em: 16 fev. 2012; aceito em 4 jul. 2013

Publicação inicial: 26 jul. 2013; versão final: 2 maio 2014
}

diferentes estratos de uma floresta (Cestaro et al. 1986). Estudos sobre estrutura e composição florística de comunidades herbáceas em florestas tropicais normalmente não se restringem às ervas, incluindo subarbustos e arbustos, além de plântulas, que são conjuntamente analisados no contexto de sub-bosque (Meira Neto \& Matins 2003; Kozera et al. 2009; Souza et al. 2009).

A riqueza de ervas, em particular, pode representar de 8 a $29 \%$ do total de espécies em florestas tropicais úmidas (Gentry \& Dodson 1987; Gentry \& Emmons 1987). Das 365 espécies de plantas vasculares não arbóreas encontradas por Gentry \& Dodson (1987) em florestas neotropicais, $13 \%$ foram somente de plantas herbáceas. Em uma floresta urbana no nordeste do Brasil, as ervas terrestres contribuíram com $31 \%$ da composição do sub-bosque (Souza et al. 2009).

No Brasil, pesquisas sobre o estrato herbáceo e/ou subarbustivo das florestas subtropicais estão concentradas na Região Sul (Citadini-Zanette 1984; Cestaro et al. 1986; Diesel \& Siqueira 1991; Dorneles \& Negrelle 1999; Müller \& Waechter 2001; Inácio \& Jarenkow 2008; Palma et al. 2008; Kozera et al. 2009), 
com poucos estudos na Amazônia (Costa 2004). Na Região Nordeste, as pesquisas sobre o estrato herbáceo em florestas ainda são incipientes. Assim, os objetivos deste estudo foram: 1- realizar um inventário das ervas terrestres em um remanescente de Floresta Estacional Semidecidual Submontana em Pernambuco; 2- caracterizar a estrutura da sinúsia herbácea; 3- caracterizar a distribuição geográfica das ervas terrestres; e 4- caracterizar as espécies de ervas em heliófitas e ciófitas.

\section{MATERIAL E MÉTODOS}

Área de estudo. A área de estudo foi a Reserva Particular do Patrimônio Natural (RPPN) Fazenda Pedra D'Anta (Figura 1), um fragmento de Floresta Estacional Semidecidual Submontana (Veloso et al. 1991) com 362 ha, localizado na Zona da Mata Sul, em Pernambuco, entre os limites dos municípios de Lagoa dos Gatos e Jaqueira, a $137 \mathrm{~km}$ de Recife (08³9'S e $\left.35^{\circ} 53^{\prime} \mathrm{W}\right)$. O clima da região é do tipo Aw, segundo a

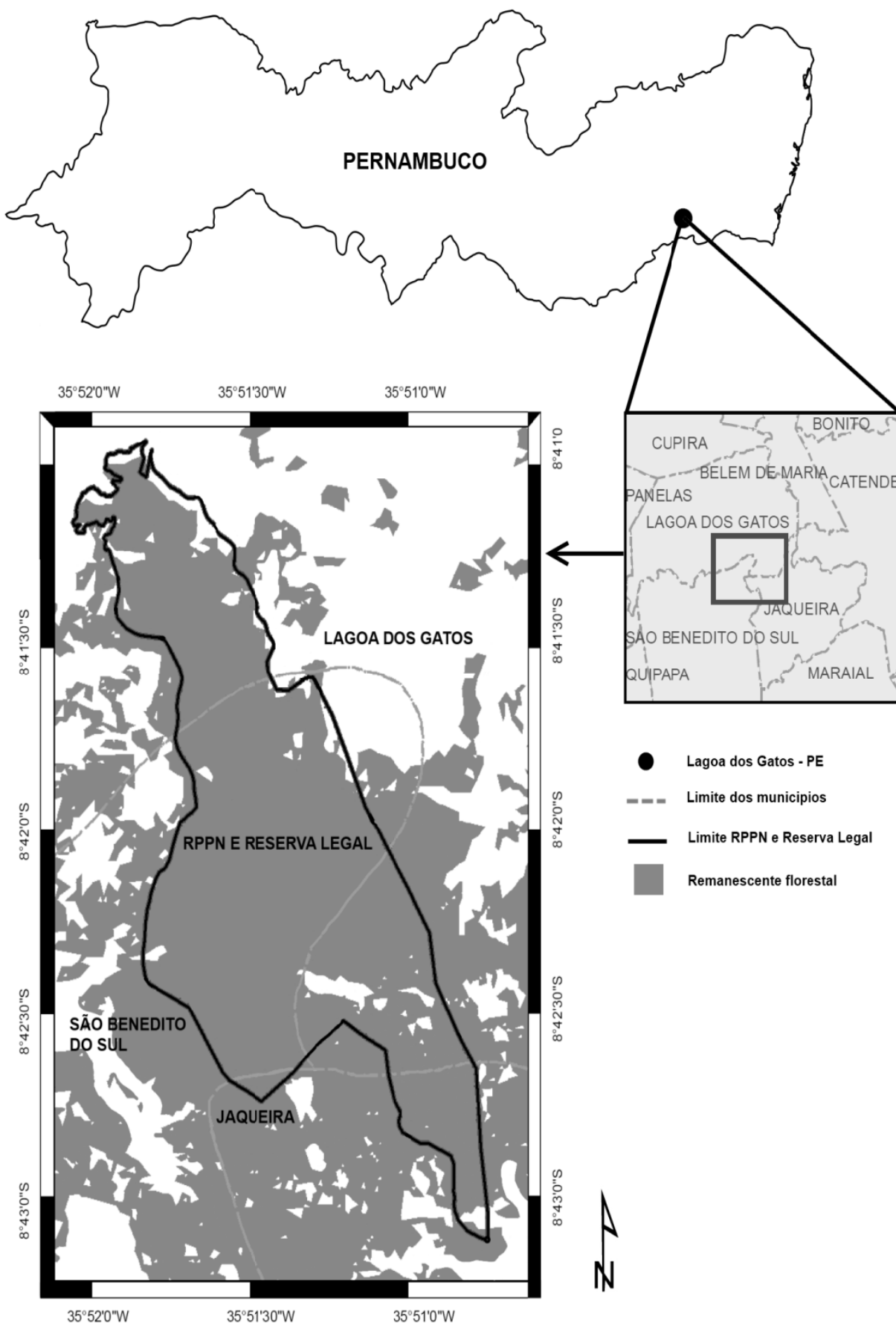

Figura 1. Mapa de localização do remanescente florestal da Reseva Particular do Patrimônio Natural Fazenda Pedra D’Anta, Lagoa dos Gatos, Pernambuco, Brasil (adaptado de Save Brasil). 
classificação de Köppen (Roda \& Carlos 2003), com precipitação média anual de $915 \mathrm{~mm}$ e temperaturas com médias anuais variando de $18^{\circ} \mathrm{C}$ a $30^{\circ} \mathrm{C}$, segundo dados meteorológicos da estação São Benedito do Sul (LAMEPE/ITEP). O relevo é bastante ondulado e fortemente acidentado, exibindo vários afloramentos rochosos, que ocorrem tanto no interior da floresta, sob sombra, quanto em descampados, em encostas inclinadas. Os solos na maior parte da área de estudo são do tipo latossolo amarelo, segundo o Mapa Exploratório-Reconhecimento de Solos do município de Lagoa dos Gatos, Pernambuco (Embrapa - Solos 2010).

A região onde está inserida a RPPN Fazenda Pedra D'Anta recebeu a classificação de IBA (Important Bird Area) pela BirdLife, sendo considerada uma das áreas prioritárias para a conservação de aves (Roda \& Carlos 2003). A RPPN caracteriza-se por concentrar remanescentes florestais no topo dos morros, como também pela presença de algumas encostas abruptas desnudas de vegetação arbórea, e de um riacho que cruza a floresta. A Fazenda Pedra D'Anta já foi uma fazenda produtiva onde se praticava monocultura de cana-de-açúcar, como em muitas outras regiões do estado de Pernambuco, e corte seletivo de madeira. Hoje, apesar de cessadas essas atividades na RPPN, a fazenda está circundada por pastagens em propriedades próximas à reserva.

Levantamento florístico e fitossociológico. $\mathrm{O}$ levantamento das ervas terrestres foi realizado em cinco expedições, entre junho de 2010 e novembro de 2011, com duração de quatro dias cada. O esforço amostral foi de aproximadamente oito horas por dia, perfazendo um total de $160 \mathrm{~h}$ de caminhadas aleatórias no interior e na borda do fragmento florestal.

Foram consideradas ervas terrestres todas as plantas vasculares autotróficas independentes, não lenhosas, fixadas no solo da floresta (Cestaro et al. 1986). Não foram incluídas no levantamento plântulas de indivíduos arbóreos, nem epífitas, trepadeiras ou saprófitas. As ervas terrestres, assim consideradas, foram coletadas e identificadas de acordo com o sistema do APG III (2009) para delimitação das famílias de angiospermas e de Smith et al. (2006) para vasculares sem sementes. As amostras foram depositadas no herbário da Universidade Federal da Paraíba (JPB), com duplicatas enviadas para os herbários da Universidade Federal de Pernambuco (UFP) e do New York Botanical Garden (NY). As formas de vida de Raunkiaer foram classificadas em caméfita, geófita, hemicriptófita e terófita (Martins \& Batalha 2011).

Para o estudo fitossociológico, a sinúsia herbácea foi amostrada em parcelas de $1 \mathrm{~m}^{2}(1 \times 1 \mathrm{~m})$. Ao todo, foram amostradas 50 parcelas, onde a primeira parcela foi sorteada, a partir da qual se traçaram transecções em orientação vertical e horizontal que distanciavam $250 \mathrm{~m}$ entre si. As ervas terrestres de cada parcela foram anotadas, quantificado-se o número de indivíduos e respectivas alturas mensuradas com uso de régua. No caso de plantas em touceiras, cada touceira foi considerada um indivíduo. Não foi estabelecida altura máxima para amostragem.

Os parâmetros fitossociológicos calculados foram densidade e frequência, absolutas e relativas (MuellerDombois \& Ellenberg 1974). Para as estimativas de riqueza e diversidade, foram utilizados o indicador de riqueza específica $(S)$ e o índice de Shannon $\left(H^{\prime}\right)$, calculados a partir de dados de frequência (Magurran 2004). A suficiência amostral foi avaliada a partir da curva do coletor. Para avaliar a distribuição espacial das espécies na sinúsia, calculou-se o Índice de Agregação de Morisita a partir da matriz de abundâncias das espécies. Considerou-se o nível de significância de $5 \%$ e o teste $\chi^{2}$ foi usado para avaliação dos padrões em relação à aleatoriedade, a $p-1$ graus de liberdade (Brower \& Zar 1977). A distribuição foi considerada aleatória quando o valor do Índice de Morisita Padronizado (I.M. Padronizado) ficou entre $-0,5$ e 0,5 . Valores menores que $-0,5$ indicaram distribuição regular e valores maiores que 0,5 indicaram distribuição agregada.

Para caracterização da distribuição geográfica das espécies, foram considerados os domínios fitogeográficos (biomas) do Brasil, segundo a Lista de Espécies da Flora do Brasil 2013 (http://floradobrasil.jbrj.gov.br/). Foram definidas duas categorias: ocorrência ampla, para aquelas espécies presentes em outros domínios Fitogeográficos além da Mata Atlântica, e ocorrência restrita, para aquelas presentes apenas na Mata Atlântica.

As parcelas foram classificadas em clareira, borda e interior a partir do ambiente onde localizavam-se no fragmento florestal. A tolerância luminosa foi então classificada, considerando ciófitas as espécies coletadas no interior da floresta e heliófitas aquelas coletadas na borda da mata ou próximo às clareiras (Rizzini 1976).

Para estimar a riqueza das espécies amostradas, foram realizados testes não paramétricos através dos estimadores Chao 2, Jacknife 1 e 2 e ainda Bootstrap, que permitem calcular o número de espécies esperado para uma determinada área.

Todas as análises foram realizadas com o uso do programa R (R Development Core Team 2011) e o pacote adicional vegan (Oksanen et al. 2011).

\section{RESUltados}

Levantamento florístico. Foram coletadas 107 espécies distribuídas em 75 gêneros e 39 famílias (Apêndice). Cinco famílias pertencem às monilófitas e as outras 34 às angiospermas. As famílias com maior riqueza foram Poaceae (14 espécies), Cyperaceae (11), Rubiaceae (7), Plantaginaceae (6), Fabaceae (6), Marantaceae (6), Commelinaceae (5), Orchidaceae (5) 
e Acanthaceae (4), que congregam 59\% das espécies. Aproximadamente $51 \%$ das famílias apresentaram somente uma espécie. A forma de vida hemicriptófita predominou $(39,26 \%$ das espécies), seguida pela terófita $(26,17 \%)$, caméfita $(25,23 \%)$ e geófita $(9,34 \%)$ (Apêndice). Com relação à tolerância luminosa, $40 \%$ das espécies foram consideradas ciófitas e as outras $60 \%$ heliófitas.

Das 92 espécies analisadas quanto à distribuição geográfica, $89 \%$ foram classificadas como de ocorrência ampla. Dentre os $11 \%$ de espécies com ocorrência restrita à Mata Atlântica, $90 \%$ são endêmicas do Brasil. Dentre as espécies de ocorrência ampla foram observados dois subgrupos, um de ocorrência apenas na Amazônia e na Mata Atlântica (9,7\% das espécies, sendo Psilochilus modestus endêmica do Brasil) e outro de ocorrência geral, com 90,3\% das espécies presentes em mais de um domínio fitogeográfico, entre Cerrado, Caatinga, Pampa e/ou Pantanal, além da Amazônia e da Mata Atlântica.

Estrutura da sinúsia. No levantamento fitossociológico, foram amostrados 1038 indivíduos, distribuídos em 25 espécies (Tabela 1). As famílias mais abundantes foram Poaceae (478 indivíduos), Cyperaceae (161), Blechnaceae (78), Lythraceae (64), Marantaceae (53) e Heliconiaceae (53). A forma de vida predominante no levantamento fitossociológico foi hemicriptófita (40\% das espécies), seguida de caméfita $(28 \%)$, geófita $(20 \%)$ e terófita $(12 \%)$.

$O$ índice de Shannon $\left(H^{\prime}\right)$ foi 2,85 nats. Os resultados obtidos com os estimadores de riqueza foram: 35,82 (Jack-1), 40,69 (Jack-2), 37,12 (Chao) e 31,09 (bootstrap). A curva do coletor indica uma tendência à estabilização do número de espécies a partir da $44^{\mathrm{a}}$ parcela (Figura 2).

Tabela 1. Parâmetros fitossociológicos das espécies herbáceas terrestres amostradas em 50 parcelas de $1 \times 1 \mathrm{~m}$ em um remanescente de Floresta Estacional Semidecidual Submontana na Reseva Particular do Patrimônio Natural Fazenda Pedra D’Anta, Lagoa dos Gatos, Pernambuco, Brasil. Ni- número de indivíduos amostrados, Ui- ocorrência da espécie i nas unidades amostrais, DA- densidade absoluta, DRdensidade relativa, FA- frequência absoluta, FR- frequência relativa. Espécies organizada em ordem crescente de frequência relativa.

\begin{tabular}{|c|c|c|c|c|c|c|}
\hline Espécies & $\mathbf{N i}$ & Ui & DA & DR & FA & FR \\
\hline Hyptis sidifolia (L'Lér.) Briq. & 10 & 1 & 0,2 & 0,96 & 2 & 0,45 \\
\hline Hygrophila costata Nees & 5 & 1 & 0,1 & 0,48 & 2 & 0,45 \\
\hline Borreria ocymifolia (Roem. \& Schult.) Bacigalupo \& E.L.Cabral & 28 & 2 & 0,56 & 2,70 & 4 & 0,91 \\
\hline Stemodia foliosa Benth. & 21 & 2 & 0,42 & 2,02 & 4 & 0,91 \\
\hline Sphagneticola trilobata (L.) Pruski & 14 & 2 & 0,28 & 1,35 & 4 & 0,91 \\
\hline Polygala paniculata L. & 12 & 2 & 0,24 & 1,16 & 4 & 0,91 \\
\hline Poaceae (morfoespécie indeterminada) & 11 & 2 & 0,22 & 1,06 & 4 & 0,91 \\
\hline Ruellia ochroleuca Mart. ex Nees & 46 & 3 & 0,92 & 4,43 & 6 & 1,36 \\
\hline Panicum sp. & 20 & 4 & 0,4 & 1,93 & 8 & 1,82 \\
\hline Costus spiralis (Jacq.) Roscoe & 7 & 4 & 0,14 & 0,67 & 8 & 1,82 \\
\hline Heliconia spathocircinata Aristeg. & 11 & 6 & 0,22 & 1,06 & 12 & 2,73 \\
\hline Blechnum occidentale L. & 78 & 7 & 1,56 & 7,51 & 14 & 3,18 \\
\hline Cuphea micrantha Kunth & 64 & 7 & 1,28 & 6,17 & 14 & 3,18 \\
\hline Rhynchospora exaltata Kunth & 18 & 7 & 0,36 & 1,73 & 14 & 3,18 \\
\hline Becquerelia cymosa Brongn. & 11 & 7 & 0,22 & 1,06 & 14 & 3,18 \\
\hline Calathea brasiliensis Körn. & 19 & 8 & 0,38 & 1,83 & 16 & 3,64 \\
\hline Monotagma plurispicatum (Körn.) K.Schum. & 16 & 8 & 0,32 & 1,54 & 16 & 3,64 \\
\hline Stromanthe tonckat (Aubl.) Eichler & 19 & 9 & 0,38 & 1,83 & 18 & 4,09 \\
\hline Adiantum lucidum (Cav.) Sw. & 10 & 9 & 0,2 & 0,96 & 18 & 4,09 \\
\hline Scleria latifolia $\mathrm{Sw}$. & 29 & 10 & 0,58 & 2,79 & 20 & 4,55 \\
\hline Panicum pilosum $\mathrm{Sw}$. & 68 & 11 & 1,36 & 6,55 & 22 & 5,00 \\
\hline Scleria bracteata Cav. & 103 & 19 & 2,06 & 9,92 & 38 & 8,64 \\
\hline Heliconia psittacorum L.f. & 42 & 20 & 0,84 & 4,05 & 40 & 9,09 \\
\hline Oplismenus hirtellus (L.) P.Beauv. & 199 & 27 & 3,98 & 19,17 & 54 & 12,27 \\
\hline Parodiolyra micrantha (Kunth) Davidse \& Zuloag & 177 & 42 & 3,54 & 17,05 & 84 & 19,09 \\
\hline TOTAIS & \multicolumn{2}{|l|}{1038} & 20,76 & 100,00 & 440 & 100,00 \\
\hline
\end{tabular}


A soma da frequência relativa das espécies de Poaceae foi de $39,09 \%$ e a das Cyperaceae foi $19,55 \%$. Parodiolyra micrantha e Oplismenus hirtellus (Poaceae) obtiveram os maiores valores de frequência absoluta (84 e 54, respectivamente) e relativa $(19,1 \%$ e $12,3 \%$ ). A densidade relativa de $P$. micrantha foi $17,05 \%$ e de $O$. hirtellus foi $19,17 \%$. Entre outras espécies com densidade relativa destacada, estão Scleria bracteata (8,48\%), Heliconia psittacorum $(8,93 \%)$ e Panicum pilosum $(4,91 \%)$.

Das 50 parcelas, $22 \%$ estavam distribuídas em parcelas de clareiras, $20 \%$ de bordas de mata e $58 \%$ no interior. Nas parcelas localizadas nas clareiras, foram registradas nove espécies, sendo 55\% ciófitas e $45 \%$ heliófitas. Nas bordas da mata, foram registradas 13 espécies: $15 \%$ ciófitas e $85 \%$ heliófitas. No interior da mata, foram registradas oito espécies, todas ciófitas (Figura 3). Houve compartilhamento de espécies principalmente entre as parcelas localizadas nas clareiras e bordas.

As plantas do estrato herbáceo apresentaram-se ora em populações densas, ora com indivíduos esparsos, com os maiores adensamentos principalmente próximos às clareiras e bordas. Na sinúsia herbácea, 95\% das espécies apresentaram distribuição agregada, com valores de I.M. Padronizado acima de 0,5 (Tabela 2). Apenas Stemodia foliosa obteve distribuição regular. As espécies Hygrophila costata e Hyptis sidifolia foram excluídas da análise porque ocorreram em uma única parcela.

A altura média dos indivíduos foi $68( \pm 60) \mathrm{cm}$, com mínima de $10 \mathrm{~cm}$ (Cuphea micrantha) e máxima de $3,2 \mathrm{~m}$ (Scleria latifolia). A distribuição dos indivíduos por classes de altura evidenciou uma grande heterogeneidade na comunidade, com predominância de indivíduos nas classes de altura $21-40 \mathrm{~cm}$ e $41-60 \mathrm{~cm}$ (Figura 4).

\section{DISCUSSÃo}

Composição e riqueza. Poaceae, Rubiaceae, Orchidaceae, Commelinaceae, Cyperaceae e Marantaceae, as famílias mais ricas em espécies neste estudo, foram citadas como as de maior riqueza no estrato herbáceo em outros sítios florestais no Brasil (Dorneles \& Negrelle 1999; Müller \& Waechter 2001; Costa 2004; Inácio \& Jarenkow 2008; Palma et al. 2008; Kozera et al. 2009). As famílias Pteridaceae e Commelinaceae também são comuns em várias formações florestais (Citadini-Zanette 1984; CitadiniZanette \& Baptista 1989; Mauhs \& Barbosa 2004; Jurinitz \& Baptista 2007; Palma et al. 2008). A representação da diversidade em ambientes tropicais se reflete no estrato herbáceo estudado, no qual $51 \%$ das famílias foram representadas por uma espécie apenas. Essa grande porcentagem de famílias com uma única espécie na área é uma característica que define o estrato herbáceo de interior de florestas tropicais (Richards 1996).

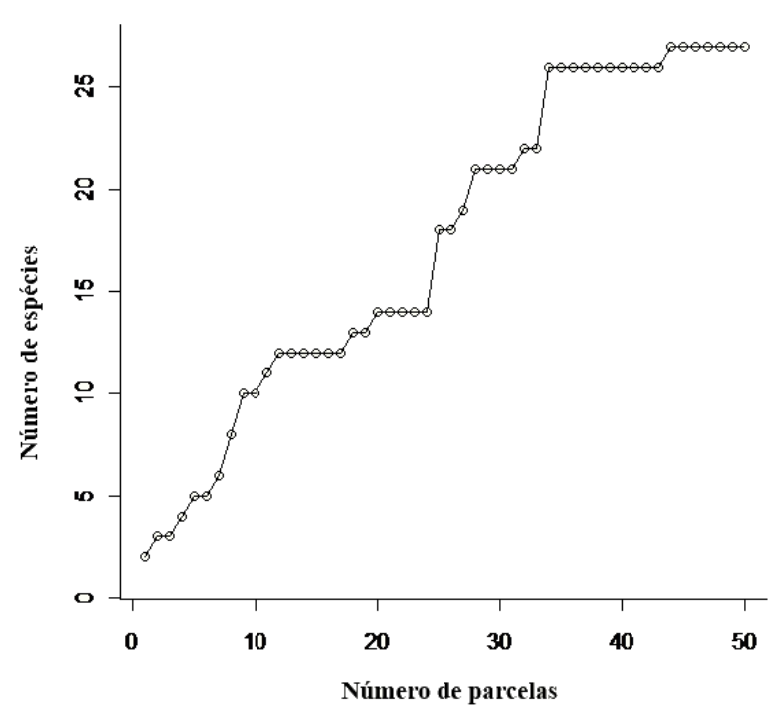

Figura 2. Curva do coletor com número de espécies amostradas em 50 parcelas de $1 \times 1 \mathrm{~m}$ na Reseva Particular do Patrimônio Natural Pedra D’Anta, Lagoa dos Gatos, Pernambuco, Brasil.

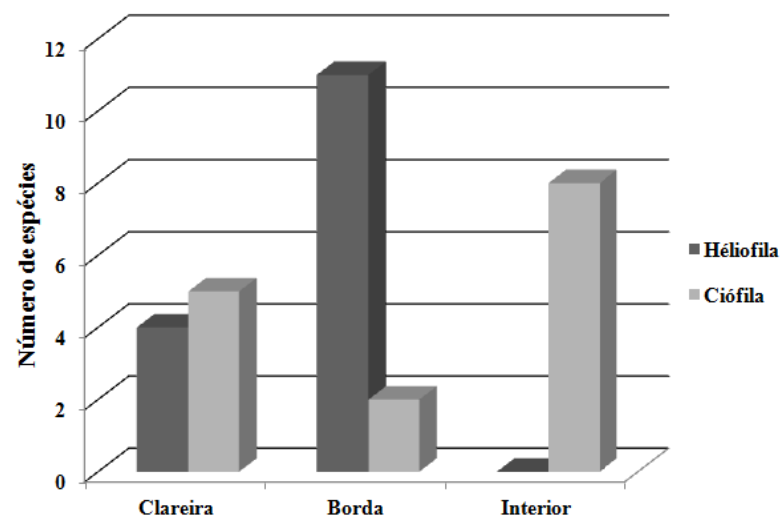

Figura 3. Proporção entre espécies herbáceas ciófitas e heliófitas delimitadas a partir das parcelas localizadas em ambiente de clareira, borda e/ou interior, no estudo fitossociológico do fragmento florestal na Reseva Particular do Patrimônio Natural Pedra D’Anta, Lagoa dos Gatos, Pernambuco, Brasil.

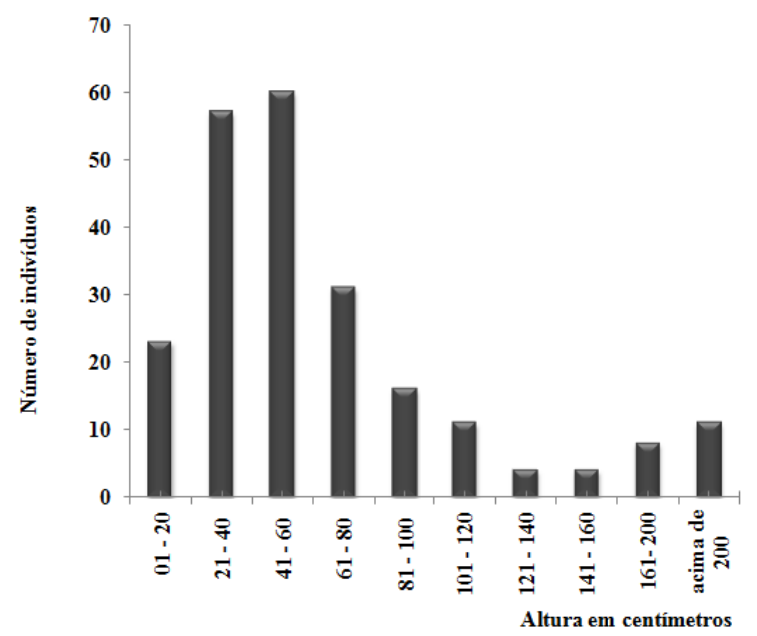

Figura 4. Estratificação dos indivíduos do estrato herbáceo por classes de altura em intervalos de $20 \mathrm{~cm}$ na Reserva Particular do Patrimônio Natural Fazenda Pedra D'Anta, Lagoa dos Gatos, Pernambuco, Brasil. 
Tabela 2. Índice de Agregação de Morisita das espécies herbáceas terrestres amostradas em um fragmento de Floresta Estacional Semidecidual Submontana na Reserva Particular do Patrimônio Natural Fazenda Pedra D’Anta, Lagoa dos Gatos, Pernambuco, Brasil. (I.M. Padronizado = Índice de Morisita Padronizado).

\begin{tabular}{|c|c|c|c|}
\hline Espécies & Índice de Morisita & I.M. Padronizado & Padrão de distribuição \\
\hline Adiantum lucidum (Cav.) Sw. & 9,72 & 0,56 & Agregado \\
\hline Becquerelia cymosa Brongn. & 16,67 & 0,63 & Agregado \\
\hline Blechnum occidentale L. & 21,43 & 0,67 & Agregado \\
\hline Borreria ocymifolia (Roem. \& Schult.) Bacigalupo \& E.L.Cabral & 50 & 1 & Agregado \\
\hline Calathea brasiliensis Körn. & 12,50 & 0,59 & Agregado \\
\hline Costus spiralis (Jacq.) Roscoe & 16,67 & 0,60 & Agregado \\
\hline Cuphea micrantha Kunth & 14,29 & 0,61 & Agregado \\
\hline Heliconia psittacorum L.f. & 13,33 & 0,59 & Agregado \\
\hline Heliconia spathocircinata Aristeg. & 5,26 & 0,53 & Agregado \\
\hline Monotagma plurispicatum (Körn.) K.Schum. & 10,71 & 0,57 & Agregado \\
\hline Oplismenus hirtellus (L.) P.Beauv. & 4,84 & 0,53 & Agregado \\
\hline Panicum pilosum $\mathrm{Sw}$. & 13,64 & 0,61 & Agregado \\
\hline Panicum sp. & 50 & 1 & Agregado \\
\hline Parodiolyra micrantha (Kunth) Davidse \& Zuloaga & 3,19 & 0,52 & Agregado \\
\hline Poaceae (morfoespécie indeterminada) & 50 & 1 & Agregado \\
\hline Polygala paniculata L. & 50 & 1 & Agregado \\
\hline Rhynchospora exaltata Kunth & 9,52 & 0,55 & Agregado \\
\hline Ruellia ochroleuca Mart. ex Nees & 16,67 & 0,57 & Agregado \\
\hline Scleria bracteata Cav. & 7,02 & 0,55 & Agregado \\
\hline Scleria latifolia Sw. & 13,33 & 0,61 & Agregado \\
\hline Sphagneticola trilobata (L.) Pruski & 50 & 1 & Agregado \\
\hline Stemodia foliosa Benth. & 0 & $-0,03$ & Regular \\
\hline Stromanthe tonckat (Aubl.) Eichler & 9,72 & 0,56 & Agregado \\
\hline
\end{tabular}

As espécies Costus spiralis, Parodiolyra micrantha, Panicum pilosum, Coccocypselum condalia e Dichorisandra hexandra, presentes neste estudo, também são citadas como principais componentes do estrato herbáceo no interior de remanescentes de Florestas Tropicais Semideciduais. Dorstenia bahiensis, presente no interior de mata, apresentou uma única e pequena população na área de estudo, localizada em um ambiente úmido próximo de rochas. Elephantopus mollis, observada em densas populações, sobretudo em lugares com dossel mais aberto, foi apontada por Cestaro et al. (1986) como característica de ambientes alterados. Destaca-se, portanto, que a presença de grande número de indivíduos da espécie observada na RPPN estudada deve-se possivelmente ao seu histórico de perturbações.

As espécies de Marantaceae são relevantes para a área estudada, uma vez que a família é característica de sub-bosque de florestas tropicais (Endress 1994; Kennedy 2000). Das 33 espécies de Marantaceae nativas do estado de Pernambuco, seis foram amostradas no presente estudo, distribuídas entre os gêneros Calathea G.Mey., Maranta L., Monotagma K.Schum. e Stromanthe Sond. Monotagma plurispicatum e Stromanthe tonckat, aqui registradas, são frequentes nos fragmentos da Zona da Mata de
Pernambuco (Leite \& Oliveira 2007), e a ocorrência de populações pequenas e restritas das espécies dessa família na RPPN é alarmante, indicando uma vulnerabilidade do grupo, principalmente devido ao aumento da fragmentação da Floresta Atlântica Nordestina (Ranta et al. 1998; Leite \& Oliveira 2007).

A análise da representatividade florística da amostragem utilizando os estimadores de riqueza revelam que, em média, poderiam ser coletadas 35 espécies. No entanto, a curva do coletor apresentou uma tendência à estabilização no número de espécies amostradas na $44^{\mathrm{a}}$ parcela, número menor que o total de parcelas adotadas (Figura 2). Obteve-se uma baixa riqueza se considerada parcela por parcela, onde a média de indivíduos foi de 4,6 e a média de espécies foi 0,42 . O pequeno tamanho das parcelas $\left(1 \mathrm{~m}^{2}\right)$ pode ter sido responsável pela baixa riqueza estimada. Esses valores podem ser um indício de que o tamanho adotado foi insuficiente para compreender uma variação expressiva na riqueza de espécies, ainda mais quando a comunidade é composta por ervas de maior porte, característica das famílias Marantaceae e Heliconiaceae, por exemplo, e até mesmo de algumas famílias de monilófitas. A aleatoriedade explica em parte a média de espécies por parcela, pois conduziu a uma discrepância na riqueza das parcelas, ora com 
muitas espécies, ora sem espécies. Das 50 parcelas, 12 não apresentaram nenhuma espécie, ressaltando a heterogeneidade espacial do estrato herbáceo.

Estrutura da sinúsia herbácea e diversidade. $\mathrm{O}$ estrato herbáceo mostrou-se bem desenvolvido em altura, com maioria dos indivíduos nas classes de 21 a $40 \mathrm{~cm}$ e de 41 a $60 \mathrm{~cm}$, com alguns indivíduos chegando a mais de $3 \mathrm{~m}$. Embora a sinúsia herbácea estudada apresente dominância em duas classes de altura, houve representação significante de indivíduos nas outras classes de altura, revelando um estrato secundário representativo. Esse estrato secundário está representado por indivíduos das classes de altura de 0 a $20 \mathrm{~cm}$, de 61 a $80 \mathrm{~cm}$ e de 80 a $100 \mathrm{~cm}$. No presente estudo, os dados de altura máxima encontrados são superiores aos encontrados por Cestaro et al. (1986) (40 cm), Dorneles \& Negrelle (1999) (70 cm) e Müller \& Waechter (2001) (2,22 m). A variação no padrão de crescimento em altura das ervas terrestres é um aspecto importante que permite deduzir as condições ambientais do local (Richards 1996). As florestas estacionais apresentam uma estação seca na qual as árvores perdem folhas, o que reduz a densidade do dossel; com isso, há uma maior penetração de radiação solar no interior da floresta (Gilliam \& Roberts 2003).

A dominância de hemicriptófitos pode ser consequência da riqueza de Poaceae e Cyperaceae. Entretanto, em outros tipos de florestas, como as Florestas Subtropicais do Sul do Brasil e mesmo as Florestas Mistas, observou-se a mesma dominância (Citadini-Zanette 1984; Cestaro et al. 1986; CitadiniZanette \& Baptista 1989; Müller \& Waechter 2001). De fato, os hemicriptófitos são reconhecidamente elementos importantes na composição e estrutura do componente herbáceo, representando a forma de vida dominante na flora mundial (Martins \& Batalha 2011).

Os terófitos constituem parte essencial na composição do estrato herbáceo da área de estudo, representando 26,16\% das espécies. As espécies que melhor representam esta forma de vida são Astrea lobata, Borreria ocymifolia, Euphorbia hyssopifolia, Physalis angulata, Polygala paniculata, Pterolepis glomerata e Torenia thouarsii. Os terófitos, em geral, são associados às espécies ruderais, invasoras de culturas e de ampla distribuição geográfica (Martins \& Batalha 2011), o que pode representar bem a situação da área com um histórico de perturbação antrópica. Coletas mensais, como também coletas adicionais logo depois de chuvas torrenciais, poderiam resultar em porcentagens mais expressivas de terófitos em invetários de plantas herbáceas, já que os terófitos têm ciclo de vida curto e, sob a forma de semente no solo, podem passar despercebidos.
Duas espécies de Poaceae caracterizaram a estrutura da sinúsia herbácea: Parodiolyra micrantha e Oplismenus hirtellus. Poaceae foi também a família de maior riqueza, com espécies mais frequentes e importantes em outras florestas do Brasil, determinando a estrutura do estrato herbáceo (Cestaro et al. 1986; Müller \& Waechter 2001; Maraschin-Silva et al. 2009; Citadini-Zanette et al. 2011). Oplismenus hirtellus aparece como a segunda espécie mais frequente e importante nos estudos de Müller \& Waechter (2001) e a terceira no de Cestaro et al. (1986). Nos resultados de Meira Neto \& Martins (2003), P. micrantha aparece entre as espécies mais importantes nos parâmetros fitossociológicos considerados. Na RPPN Fazenda Pedra D'Anta, a importância de Poaceae deve-se principalmente à sua levada riqueza e abundância. A densidade relativa de P. micrantha $(17,05 \%)$ e O. hirtellus $(19,17 \%)$ indica como essas espécies ocupam o espaço na comunidade.

Outras famílias também importantes no levantamento fitossociológico foram Heliconiaceae, representada por Heliconia psittacorum, com frequência absoluta (FA) 40, e $H$. spathocircinata, com 12. Apesar de Marantaceae ter uma espécie a mais que Heliconiaceae - Calathea brasiliensis (FA 16), Monotagma plurispicatum (FA 16) e Stromanthe tonckat (FA 18) - a soma dos valores de frequência absoluta das espécies de Heliconiaceae ultrapassa a de Marantaceae. Ambas as famílias apresentam espécies geralmente encontradas no interior de florestas e de ampla distribuição (Forzza et al. 2011).

A diversidade específica obtida neste estudo (2,85 nats) foi próxima à média de 2,56 nats obtida nas pesquisas realizadas em outros sítios florestais no Brasil (Müller \& Waechter 2001; Inácio \& Jarenkow 2008; Palma et al. 2008), evidenciando um certo padrão estrutural do estrato herbáceo em Florestas Estacionais Semideciduais e Subtropicais.

Ocorrência geográfica das espécies. Embora o estrato herbáceo da RPPN estudada tenha predominância de espécies de ocorrência ampla, ele apresenta o endemismo característico do bioma Mata Atlântica, com $11 \%$ das espécies restritas à Mata Atlântica, sendo quase todas endêmicas do Brasil (Aechmea tomentosa, Borreria humifusa, Calathea brasiliensis, Ctenanthe casupoides, Dichorisandra thyrsiflora, Dorstenia bahiensis, Hypolithrum bullatum, Maranta noctiflora e Neomarica occidentalis), com exceção de Hyptis sidifolia.

Anemia phyllitidis, Elephnatopus mollis e Oplismenus hirtellus também estão presentes no estrato herbáceo de Florestas Subtropicais e Tropicais Estacionais Semideciduais (Cestaro et al. 1986; Müller \& Waechter 2001; Meira Neto \& Martins 2003; Kozera et al. 2009; Palma et al. 2008). Essas espécies ocorrem por toda a América do Sul, sendo que, no Brasil, 
ocorrem praticamente em todos os domínios ('biomas', Forzza et al. 2011).

Streptochaeta spicata e Psilochilus modestus estão presentes em toda Mata Atlântica das Regiões Sul e Sudeste do Brasil, com a primeira estendendo-se aos estados da Bahia e Ceará, no Nordeste. Ambas ocorrem no bioma Floresta Amazônica e não haviam sido registradas no estado de Pernambuco. As demais espécies, incluindo nativas ou não, ocorrem em todos os Domínios Fitogeográficos brasileiros, além da Mata Atlântica.

Herbáceas e ambiente. $O$ estrato herbáceo da área de estudo apresentou, principalmente, espécies tolerantes à luz solar em ambientes de borda e clareira. A predominância de plantas heliófitas era esperada e essa predominância está ligada à estrutura da abertura no dossel e ao tipo de ambiente em que foram encontradas. As espécies de Cyperaceae estiveram mais presentes nesses ambientes, como Scleria bracteata, por exemplo, que ocorreu exclusivamente sob o sol.

A condição ambiental da floresta foi afetada pelo histórico de perturbações, como o plantio de cana-deaçúcar, corte seletivo de árvores e presença de pastagens no entorno, o que deve ter influenciado a composição florística, estrutura e o número de espécies presentes. A área de estudo apresenta variações no relevo quanto à altitude e declividade, o que propicia uma diversidade de hábitats. Nas bordas e em clareiras da floresta, são relativamente comuns Rhynchospora exaltata, $R$. nervosa e Scleria bracteata. Também, ocorrem espécies reconhecidamente invasoras de culturas, como Commelina diffusa, Phytolacca thryrsiflora e Setaria vulpiseta. Parodiolyra micrantha (Poaceae) domina muitos trechos da floresta, mas existem trechos onde a espécie não ocorre ou não forma adensamentos. Cuphea micrantha é uma espécie abundante nas bordas da floresta e em trilhas mais ou menos abertas, mas não foi encontrada nas bordas das clareiras e nem no interior da floresta.

\section{CONCLUSÃo}

A RPPN Fazenda Pedra D'Anta está estabelecida em uma paisagem fragmentada devido ao histórico de uso da terra. Esta situação se reflete na composição da flora herbácea, que apresenta várias espécies ruderais. Todavia, o difícil acesso à região a torna um refúgio para algumas espécies raras como Psilochilus modestus e Stretochaeta spicata, que têm aqui os seus primeiros registros para Pernambuco. O estrato herbáceo da floresta estudada apresenta características comuns às florestas tropicais, com grande número de famílias representadas por uma espécie. Apresenta composição florística formada predominantemente por espécies de ampla distribuição, que ocorrem tanto em Florestas Estacionais Semideciduais como em Florestas
Subtropicais, bem como em outros biomas. A estrutura dessa sinúsia herbácea apresenta padrão florísticoestrutural similar ao de outras florestas, principalmente devido à família Poaceae.

\section{AgRADECIMENTOS}

À Save Brasil, pela autorização de pesquisa na área. Ao Projeto Floresta Atlântica/CNPq/NSF, pelo apoio financeiro; à CAPES, pela bolsa de pós-graduação à primeira autora; e ao Programa de Pós-Graduação em Biologia Vegetal - PPGBV. À Wayt Thomas, pela identificação de Cyperaceae; e aos amigos José Roberto Lima, Manoel da Silva Flor e José Antônio Vicente Filho, pelo apoio no trabalho de campo.

\section{REFERÊNCIAS}

APG III. 2009. An update of the Angiosperm Phylogeny Group classification for the orders and families of flowering plants: APG III. Botanical Journal of the Linnean Society 16(2): 105121.

Brower, J.E. \& Zar, J.H. 1977. Biotic Sampling Methods. In J.E. Brower \& J.H. Zar (eds), Field and Laboratory Methods for General Ecology. Wm. C. Brown, Iowa, p. 65-105.

Cestaro, L.A.; Waechter, J.L. \& Baptista, L.R.M. 1986. Fitossociologia do estrato herbáceo da Mata de Araucária da Estação Ecológica de Aracuri, Esmeralda, RS. Hoehnea 13: 5972.

Citadini-Zanette, V. 1984. Composição florística e fitossociologica da vegetação herbácea terrícola de uma mata de Torres, Rio Grande do Sul, Brasil. Iheringia série Botânica 32: 23-62.

Citadini-Zanette, V. \& Baptista, L.R.M. 1989. Vegetação herbácea terrícola de uma comunidade florestal em Limoeiro, Município de Torres, Rio Grande do Sul. Boletim do Instituto de Biociências 45: 1-87.

Citadini-Zanette, V.; Pereira, J.L.; Jarenkow, J.A.; Klein, A.S. \& Santos, R. 2011. Estrutura da sinúsia herbácea em Floresta Ombrófila Mista no Parque Nacional de Aparados da Serra, Sul do Brasil. Revista Brasileira de Biociências 9(1): 56-63.

Costa, F.R.C. 2004. Structure and composition of the ground-herb community in a terra-firme Central Amazonian forest. Acta Amazonica 34(1): 53-59.

Diesel, S. \& Siqueira, J.C. 1991. Estudo fitossociológico herbáceo/arbustivo da mata ripária da bacia hidrográfica do Rio dos Sinos, RS. Pesquisas, série Botânica 42: 201-257.

Dorneles, L.P.P. \& Negrelle, R.R.B. 1999. Composição florística e estrutura do compartimento herbáceo de um estágio sucessional avançado da Floresta Atlântica, no Sul do Brasil. Biotemas 12(2): 7-30.

Embrapa-Solos 2010. Empresa Brasileira de Pesquisas Agronômicas. Disponível em $<\mathrm{http} / / /$ www.uep.cnps.embrapa.br /solos/pe/lagoadosgatos.pdf $>$; acesso em 17 maio 2010.

Endress, P.K. 1994. Diversity and Evolutionary Biology of Tropical Flowers. Pergamon Press, Oxford.

Gentry, A.H. 1988. Changes in plant community diversity and floristic composition on environmental and geographical gradients. Annals of the Missouri Botanical Garden 75(1): 1-34. 
Gentry, A.H. \& Dodson, C. 1987. Contribution of nontrees to species richness of a Tropical rain forest. Biotropica 19(2): $149-156$.

Gentry, A.H. \& Emmons, L.H. 1987. Geographical variation in fertility, phenology, and composition of the understory of neotropical forests. Biotropica 19(3): 216-227.

Gilliam, F.S. 2007. The ecological significance of the herbaceous layer in Temperate forest ecosystems. Bioscience 57(10): 845858.

Gilliam, F.S. \& Roberts, M.R. 2003. Introduction: conceptual framework for studies of the herbaceous layer. In: F.S. Gilliam \& M.R. Roberts (eds), The Herbaceous Layer in Forests of Eastern North America. Oxford University Press, New York, p. $3-14$.

Inácio, C.D. \& Jarenkow, J.A. 2008. Relações entre a estrutura da sinúsia herbácea terrícola e a cobertura do dossel em Floresta Estacional no Sul do Brasil. Revista Brasileira de Botânica 31(1): 41-51.

Jurinitz, C.F. \& Baptista, L.R.M. 2007. Monocotiledôneas terrícolas em um fragmento de Floresta Ombrófila Densa no Litoral Norte do Rio Grande do Sul. Revista Brasileira de Biociencias 5(1): 9-17.

Kennedy, H. 2000. Diversification in pollination mechanisms in the Marantaceae. In: K.L. Wilson \& D.A. Morrison (eds), Monocots: systematics and evolution. Publishing Collingwood, Sydney, p. 335-344.

Kozera, C.; Rodrigues, R.R. \& Dittrich, V.A.O. 2009 composição florística do sub-bosque de uma Floresta Ombrófila Densa Montana, Morretes, PR, Brasil. Floresta 39(2): 323-334.

Leite, M.S. \& Oliveira, J.B. 2007. A família Marantaceae nos herbários do estado de Pernambuco: distribuição e conservação. Revista Brasileira de Biociências 5(suppl. 2): 789-791.

Lima, R.A.F. \& Gandolfi, S. 2009. Structure of the herb stratum under different light regimes in the submontane Atlantic rain forest. Brazilian Journal of Biology 69(2): 289-296.

Magurran, A.E. 2004. Measuring Biological Diversity. Blackwell, Malden.

Maraschin-Silva, F.; Adriano Scherer, A. \& Luís Baptista, L.R.M. 2009. Diversidade e estrutura do componente herbáceosubarbustivo em vegetação secundária de Floresta Atlântica no Sul do Brasil. Revista Brasileira de Biociências 7(1): 53-65.

Martins, F.R. \& Batalha, M.A. 2011. Formas de vida, espectro biológico de Raunkiaer e fisionomia da vegetação. In: J.M. Felfili, P.V. Eisenlohr, M.M.R.F. Melo, L.A. Andrade \& J.A.A. Meira Neto (orgs), Fitossociologia no Brasil: métodos e estudos de casos. Vol. 1. Editora UFV, Viçosa, p. 44-85.

Mauhs, J. \& Barbosa, J.F. 2004. Levantamento do componente herbáceo em Floresta de Restinga Psamófila, Palmares do Sul, RS. Pesquisas, série Botânica 55: 137-141.
Meira Neto, J.A.A. \& Martins, F.R. 2003. Estrutura do subbosque herbáceo-arbustivo da Mata da Silvicultura, uma Floresta Estacional Semidecidual no Município de Viçosa-MG. Revista Árvore 27(4): 459-471.

Mueller-Dombois, D. \& Ellenberg, H. 1974. Aims and Methods of Vegetation Ecology. John Wiley, New York.

Müller, S.C. \& Waechter, J.L. 2001. Estrutura sinusial dos componentes herbáceo e arbustivo de uma Floresta Costeira Subtropical. Revista Brasileira de Botânica 24(4): 395-406.

Oksanen, F.J.; Blanchet, G.; Kindt, R.; Legendre, P.; O'hara, R.B.; Simpson, G. L.; Solymos, P.; Stevens M.H.H. \& Wagner, H. 2011. Vegan: community ecology package. R package version 1.17-6. Disponível em <http://cran.rproject.org/package=vegan $>$; acesso em 18 mar. 2011.

Palma, C.B.; Inácio, C.D. \& Jarenkow, J.A. 2008. Florística e estrutura da sinúsia herbácea terrícola de uma Floresta Estacional de Encosta no Parque Estadual de Itapuã, Viamão, Rio Grande do Sul, Brasil. Revista Brasileira de Biociências 6(3): 151-158.

R Development Core Team (2011). $R:$ a language and environment for statistical computing. $\mathrm{R}$ Foundation for Statistical Computing, Vienna. Disponível em $<$ http://www.Rproject.org/>; acesso em 17 maio 2010.

Ranta, P.; Brom, T.; Joensuu, E. \& Mikko, S. 1998. The fragmented Atlantic forest of Brazil: size, shape and distribution of forest fragments. Biodiversity and Conservation 7(3): 385403.

Richards, P.W. 1996. The Tropical Rain Forest: an ecological study. 2. ed. Cambridge University Press, Cambridge

Rizzini, C.T. 1976. Tratado de Fitogeografia do Brasil. Vol. 2. Editora da Universidade de São Paulo, São Paulo.

Roda, S.A. \& Carlos, C.J. 2003. New records for some poorly known birds of Atlantic forest of northeastern Brazil. Cotinga 20: $17-20$.

Smith, A.R.; Pryer, K.M.; Schuettpelz, E.; Korall, P.; Schneider, H. \& Wolf, P.G. 2006. A classification for extant ferns. Taxon 55(3): 705-731.

Soares Jr, R.C.; Almeida Jr, E.B.; Pessoa, L.M.; Pimentel, R.M.M. \& Zickel, C.S. 2008. Flora do estrato herbáceo em um fragmento urbano de Floresta Atlântica - PE. Revista de Geografia 25(1): 35-49.

Souza, A.C.R.; Almeida Jr, E.B. \& Zickel, C.S. 2009. Riqueza de espécies de sub-bosque em um fragmento florestal urbano, Pernambuco, Brasil. Biotemas 22(3): 57-66.

Veloso, H.P.; Rangel Filho, A.L.R. \& Lima, J.C.A. 1991. Classificação da Vegetação Brasileira, Adaptada a um Sistema Universal. IBGE, Rio de Janeiro. 
Apêndice. Famílias e espécies de ervas terrestres amostradas em um remanescente de Floresta Estacional Semidecidual Submontana na Reserva Particular do Patrimônio Natural Fazenda Pedra D’Anta, Lagoa dos Gatos, Pernambuco, Brasil. Ambiente quanto à preferência de luminosidade e formas de vida.

\begin{tabular}{|c|c|c|c|}
\hline Família/Espécies & Material-testemunho & $\begin{array}{c}\text { Torelância } \\
\text { luminosa }\end{array}$ & $\begin{array}{c}\text { Formas de } \\
\text { vida }\end{array}$ \\
\hline \multicolumn{4}{|l|}{ MONILÓFITAS } \\
\hline \multicolumn{4}{|l|}{ Anemiaceae } \\
\hline Anemia phyllitidis (L.) Sw. & Viana, J.L. et al. 101 & Ciófita & Hemicriptófita \\
\hline \multicolumn{4}{|l|}{ Blechnaceae } \\
\hline Blechnum occidentale L. & Viana, J.L. 190 & Heliófita & Hemicriptófita \\
\hline \multicolumn{4}{|l|}{ Pteridaceae } \\
\hline Adiantum lucidum (Cav.) Sw. & Viana, J.L. 276 & Ciófita & Hemicriptófita \\
\hline Adiantum terminatum Kunze ex Miq. & Viana, J.L. \& Machado, E.O. 292 & Ciófita & Hemicriptófita \\
\hline \multicolumn{4}{|l|}{ Tectariaceae } \\
\hline Triplophyllum boliviense J.Prado \& R.C.Moran & Viana, J.L. \& Machado, E.O. 291 & Ciófita & Hemicriptófita \\
\hline \multicolumn{4}{|l|}{ Thelypteridaceae } \\
\hline Thelypteris hispidula (Decne.) C.F.Reed & Viana, J.L. \& Machado, E.O. 301 & Ciófita & Hemicriptófita \\
\hline \multicolumn{4}{|l|}{ ANGIOSPERMAS } \\
\hline \multicolumn{4}{|l|}{ Acanthaceae } \\
\hline Hygrophila costata Nees & Viana, J.L. 199 & Heliófita & Caméfita \\
\hline Ruellia geminiflora Kunth & Viana, J.L. 198 & Heliófita & Caméfita \\
\hline Ruellia ochroleuca Mart. ex Nees & Viana, J.L. et al. 115 & Heliófita & Caméfita \\
\hline Dicliptera mucronifolia Nees & Viana, J.L. et al. 351 & Ciófita & Caméfita \\
\hline \multicolumn{4}{|l|}{ Amaranthaceae } \\
\hline Pffafia sp. & Viana, J.L. 174 & Heliófita & Terófita \\
\hline \multicolumn{4}{|l|}{ Amaryllidaceae } \\
\hline Hippeastrum puniceum (Lam.) Kuntze & Viana, J.L. et al. 338 & Heliófita & Geófita \\
\hline \multicolumn{4}{|l|}{ Asteraceae } \\
\hline Elephantopus mollis Kunth & Viana, J.L. et al. 333 & Heliófita & Terófita \\
\hline Erechtites valerianifolius (Wolf) DC. & Viana, J.L. et al. 348 & Heliófita & Terófita \\
\hline Sphagneticola trilobata (L.) Pruski & Viana, J.L. 250 & Heliófita & Caméfita \\
\hline \multicolumn{4}{|l|}{ Bromeliaceae } \\
\hline Aechmea tomentosa $\mathrm{Mez}$ & Viana, J.L. et al. 124 & Ciófita & Hemicriptófita \\
\hline \multicolumn{4}{|l|}{ Campanulaceae } \\
\hline Lobelia xalapensis Kunth & Viana, J.L. et al. 327 & Heliófita & Terófita \\
\hline \multicolumn{4}{|l|}{ Commelinaceae } \\
\hline Commelina diffusa Burm.f. & Viana, J.L. 286 & Heliófita & Hemicriptófita \\
\hline Commelina rufipens Seub. & Viana, J.L. 283 & Ciófita & Hemicriptófita \\
\hline Dichorisandra hexandra (Aubl.) Standl. & Viana, J.L. \& Machado, E.O. 293 & Ciófita & Hemicriptófita \\
\hline Dichorisandra thyrsiflora J.L.Mikan & Viana, J.L. \& Machado, E.O. 305 & Ciófita & Hemicriptófita \\
\hline Gibasis geniculata (Jacq.) Rohweder & Viana, J.L. et al. 91 & Ciófita & Hemicriptófita \\
\hline \multicolumn{4}{|l|}{ Costaceae } \\
\hline Costus spiralis (Jacq.) Roscoe & Viana, J.L. et al. 77 & Ciófita & Hemicriptófita \\
\hline \multicolumn{4}{|l|}{ Cyperaceae } \\
\hline Becquerelia cymosa Brongn. & Viana, J.L. et al. 111 & Ciófita & Hemicriptófita \\
\hline Cyperus laxus Lam. & Viana, J.L. 251 & Heliófita & Hemicriptófita \\
\hline Cyperus surinamensis Rottb. & Viana, J.L. 259 & Heliófita & Hemicriptófita \\
\hline Hypolytrum bullatum C.B.Clarke & Thomas, W.W. et al. 15288 & Ciófita & Hemicriptófita \\
\hline Hypolytrum schraderianum Nees & Viana, J.L. \& Machado, E.O. 309 & Ciófita & Hemicriptófita \\
\hline Rhynchospora cephalotes (L.) Vahl & Viana, J.L. 247 & Heliófita & Hemicriptófita \\
\hline
\end{tabular}


Apêndice (continuação)

\begin{tabular}{|c|c|c|c|}
\hline Família/Espécies & Material-testemunho & $\begin{array}{c}\text { Torelância } \\
\text { luminosa }\end{array}$ & $\begin{array}{l}\text { Formas de } \\
\text { vida }\end{array}$ \\
\hline Rhynchospora exaltata Kunth & Viana, J.L. \& Machado, E.O. 310 & Heliófita & Hemicriptófita \\
\hline Rhynchospora nervosa (Valh) Boeckeler & Viana, J.L. 253 & Heliófita & Hemicriptófita \\
\hline Rhynchospora radicans (Schltdl. \& Cham.) H.Pfeiff. & Viana, J.L. et al. 299 & Heliófita & Hemicriptófita \\
\hline Scleria bracteata Cav. & Viana, J.L. et al. 110 & Heliófita & Hemicriptófita \\
\hline Scleria latifolia Sw. & Viana, J.L. et al. 109 & Heliófita & Hemicriptófita \\
\hline \multicolumn{4}{|l|}{ Euphorbiaceae } \\
\hline Astraea lobata (L.) Klotzsch & Viana, J.L. et al. 329 & Heliófita & Terófita \\
\hline Euphorbia hyssopifolia $\mathrm{L}$. & Viana, J.L. et al. 350 & Heliófita & Terófita \\
\hline \multicolumn{4}{|l|}{ Fabaceae } \\
\hline Aeschynomene sp. & Viana, J.L. et al. 94 & Heliófita & Caméfita \\
\hline Crotalaria stipularia Desv. & Viana, J.L. et al. 142 & Heliófita & Caméfita \\
\hline Crotalaria sp. & Viana, J.L. 180 & Heliófita & Caméfita \\
\hline Desmodium sp. 1 & Viana, J.L. 250 & Heliófita & Caméfita \\
\hline Desmodium sp. 2 & Viana, J.L. 257 & Heliófita & Caméfita \\
\hline Fabaceae indeterminada & Viana, J.L. 173 & Heliófita & Caméfita \\
\hline \multicolumn{4}{|l|}{ Gentianaceae } \\
\hline Coutoubea spicata Aubl. & Viana, J.L. et al. 353 & Heliófita & Terófita \\
\hline Chelonanthus purpurascens (Aubl.) Struwe \& V.A.Albert & Viana, J.L. et al. 92 & Heliófita & Caméfita \\
\hline \multicolumn{4}{|l|}{ Heliconiaceae } \\
\hline Heliconia psittacorum L.f. & Viana, J.L. 237 & Ciófita & Geófita \\
\hline Heliconia spathocircinata Aristeg. & Viana, J.L. et al. 336 & Ciófita & Geófita \\
\hline \multicolumn{4}{|l|}{ Iridaceae } \\
\hline Neomarica occidentalis (Baker) Sprague & Viana, J.L. 169 & Ciófita & Geófita \\
\hline \multicolumn{4}{|l|}{ Lamiaceae } \\
\hline Hyptis pectinata (L.) Poit & Viana, J.L. et al. 70 & Heliófita & Caméfita \\
\hline Hyptis sidifolia (L'Lér.) Briq. & Viana, J.L. 205 & Heliófita & Caméfita \\
\hline \multicolumn{4}{|l|}{ Linderniaceae } \\
\hline Lindernia dubia (L.) Pennell & Viana, J.L. \& Machado, E.O. 320 & Heliófita & Terófita \\
\hline Torenia thouarsii (Cham. \& Schltdl.) Kuntze & Viana, J.L. 252 & Heliófita & Terófita \\
\hline \multicolumn{4}{|l|}{ Loganiaceae } \\
\hline Spigelia sp. & Viana, J.L. 280 & Ciófita & Caméfita \\
\hline \multicolumn{4}{|l|}{ Lythraceae } \\
\hline Cuphea campestris Koehne & Viana, J.L. et al. 331 & Heliófita & Caméfita \\
\hline Cuphea micrantha Kunth & Viana, J.L. 200 & Heliófita & Caméfita \\
\hline \multicolumn{4}{|l|}{ Marantaceae } \\
\hline Calathea brasiliensis Körn. & Viana, J.L. 271 & Ciófita & Geófita \\
\hline Ctenanthe casupoides Petersen & Viana, J.L. 264 & Ciófita & Geófita \\
\hline Ctenanthe glabra (Körn.) Eichler & Viana, J.L. 238 & Ciófita & Geófita \\
\hline Maranta noctiflora Regel \& Körn. & Viana, J.L. \& Machado, E.O. 297 & Heliófita & Caméfita \\
\hline Monotagma plurispicatum (Körn.) K.Schum. & Viana, J.L. 165 & Ciófita & Geófita \\
\hline Stromanthe tonckat (Aubl.) Eichler & Viana, J.L. 184 & Ciófita & Caméfita \\
\hline \multicolumn{4}{|l|}{ Moraceae } \\
\hline Dorstenia bahiensis Klotzsch ex Fisch. \& C.A.Mey. & Viana, J.L. 206 & Ciófita & Hemicriptófita \\
\hline \multicolumn{4}{|l|}{ Ochnaceae } \\
\hline Sauvagesia erecta $\mathrm{L}$. & Viana, J.L. et al. 373 & Heliófita & Terófita \\
\hline \multicolumn{4}{|l|}{ Melastomataceae } \\
\hline Pterolepis trichotoma (Rottb.) Cogn. & Viana, J.L. et al. 324 & Heliófita & Terófita \\
\hline Pterolepis glomerata (Rottb.) Miq. & Viana, J.L. et al. 325 & Heliófita & Terófita \\
\hline
\end{tabular}


Apêndice (continuação)

\begin{tabular}{|c|c|c|c|}
\hline Família/Espécies & Material-testemunho & $\begin{array}{c}\text { Torelância } \\
\text { luminosa }\end{array}$ & $\begin{array}{c}\text { Formas de } \\
\text { vida } \\
\end{array}$ \\
\hline \multicolumn{4}{|l|}{ Orchidaceae } \\
\hline Psilochilus modestus Barb. Rodr & Viana, J.L. et al. 121 & Ciófita & Terófita \\
\hline Aspidogyne foliosa (Poepp. \& Endl.) Garay & Viana, J.L. 242 & Ciófita & Terófita \\
\hline Habenaria trifida Kunth & Viana, J.L. \& Machado, E.O. 295 & Heliófita & Terófita \\
\hline Liparis nervosa (Thumb.) Lindl. & Viana, J.L. \& Machado, E.O. 303 & Ciófita & Terófita \\
\hline Malaxis excavata (Lind1.) Kuntze & Viana, J.L. \& Machado, E.O. 307 & Ciófita & Terófita \\
\hline \multicolumn{4}{|l|}{ Orobanchaceae } \\
\hline Melasma melampyroides (Rich.) Pennell & Viana, J.L. et al. 326 & Heliófita & Terófita \\
\hline \multicolumn{4}{|l|}{ Oxalidaceae } \\
\hline Oxalis cratensis Oliv. ex Hook. & Viana, J.L. et al. 323 & Heliófita & Terófita \\
\hline \multicolumn{4}{|l|}{ Phytolaccaceae } \\
\hline Phytolacca thyrsiflora Fenzl ex J.A. Schmidt. & Viana, J.L. et al. 98 & Heliófita & Caméfita \\
\hline \multicolumn{4}{|l|}{ Plantaginaceae } \\
\hline Achetaria scutellarioides (Benth.) Wettst. & Viana, J.L. 162 & Heliófita & Caméfita \\
\hline Angelonia biflora Benth. & Viana, J.L. 281 & Heliófita & Terófita \\
\hline Bacopa sp. 1 & Viana, J.L. et al. 347 & Heliófita & Caméfita \\
\hline Bacopa stricta (Schrad.) Wettst. ex Edwall & Viana, J.L. \& Machado, E.O. 290 & Heliófita & Caméfita \\
\hline Stemodia foliosa Benth. & Viana, J.L. 204 & Heliófita & Caméfita \\
\hline Stemodia verticillta (Mill.) Hassl. & Viana, J.L. \& Machado, E.O. 321 & Heliófita & Caméfita \\
\hline \multicolumn{4}{|l|}{ Poaceae } \\
\hline Dichanthelium assurgens (Renvoize) Zuloaga & Viana, J.L. 255 & Heliófita & Hemicriptófita \\
\hline Ichnanthus calvescens Nees & Viana, J.L. et al. 135 & Ciófita & Hemicriptófita \\
\hline Ichnanthus nemoralis (Schrad. ex Schult.) Hitchc. \& Chase & Viana, J.L. 262 & Ciófita & Hemicriptófita \\
\hline Ichnanthus tenuis (J.Presl \& C.Presl) Hitchc. \& Chase & Viana, J.L. 285 & Ciófita & Hemicriptófita \\
\hline Ichnanthus sp. & Viana, J.L. 248 & Ciófita & Hemicriptófita \\
\hline Lasiacis sorghoidea (Ham.) Hitchc. \& Chase & Viana, J.L. et al. 106 & Heliófita & Hemicriptófita \\
\hline Olyra latifolia $\mathrm{L}$. & Viana, J.L. 275 & Heliófita & Hemicriptófita \\
\hline Oplismenus hirtellus (L.) P.Beauv. & Viana, J.L. 194 & Ciófita & Hemicriptófita \\
\hline Panicum pilosum Sw. & Viana, J.L. 260 & Heliófita & Hemicriptófita \\
\hline Panicum sp. & Viana, J.L. et al.107 & Heliófita & Hemicriptófita \\
\hline Parodiolyra micrantha (Kunth) Davidse \& Zuloaga & Viana, J.L. et al. 105 & Ciófita & Hemicriptófita \\
\hline Setaria vulpiseta (Lam.) Roem. \& Schult. & Viana, J.L. 279 & Heliófita & Hemicriptófita \\
\hline Streptochaeta spicata Schrad. ex Nees & Viana, J.L. et al. 341 & Ciófita & Hemicriptófita \\
\hline Poaceae indeterminada & Viana, J.L. et al. 332 & Heliófita & Hemicriptófita \\
\hline \multicolumn{4}{|l|}{ Polygalaceae } \\
\hline Polygala paniculata $\mathrm{L}$. & Viana, J.L. \& Machado, E.O. 296 & Heliófita & Terófita \\
\hline Polygala violacea Aubl. & Viana, J.L. et al. 137 & Heliófita & Terófita \\
\hline \multicolumn{4}{|l|}{ Rubiaceae } \\
\hline Borreria humifusa Mart. & Viana, J.L. 191 & Ciófita & Terófita \\
\hline Borreria latifolia (Aubl.) K.Schum. & Viana, J.L. \& Machado, E.O. 317 & Heliófita & Terófita \\
\hline $\begin{array}{l}\text { Borreria ocymifolia (Roem. \& Schult.) Bacigalupo \& } \\
\text { E.L.Cabral }\end{array}$ & Viana, J.L. 273 & Heliófita & Terófita \\
\hline Borreria scabiosoides Cham. \& Schtdl. & Viana, J.L. \& Machado, E.O. 308 & Heliófita & Caméfita \\
\hline Coccocypselum condalia Pers. & Viana, J.L. 256 & Ciófita & Hemicriptófita \\
\hline Coccocypselum cordifolium Nees \& Mart. & Viana, J.L. 249 & Ciófita & Hemicriptófita \\
\hline Geophila repens (L.) I.M.Johnst. & Viana, J.L. 261 & Ciófita & Hemicriptófita \\
\hline \multicolumn{4}{|l|}{ Solanaceae } \\
\hline Physalis angulata $\mathrm{L}$. & Viana, J.L. et al. 351 & Heliófita & Terófita \\
\hline \multicolumn{4}{|l|}{ Urticaceae } \\
\hline Pilea hyalina Fenzl & Viana, J.L. \& Machado,E.O. 289 & Heliófita & Terófita \\
\hline
\end{tabular}


Apêndice (continuação)

\begin{tabular}{lccc}
\hline Família/Espécies & Material-testemunho & $\begin{array}{c}\text { Torelância } \\
\text { luminosa }\end{array}$ & $\begin{array}{c}\text { Formas de } \\
\text { vida }\end{array}$ \\
\hline Violaceae & Viana, J.L. et al. 322 & Heliófita & Terófita \\
$\begin{array}{l}\text { Hybanthus calceolaria } \text { (L.) Oken } \\
\text { Zingiberaceae }\end{array}$ & Viana, J.L. \& Machado, E.O. 312 & Ciófita & Geófita \\
Renealmia alpinia (Rottb.) Maas & Viana, J.L. et al. 334 & Ciófita & Geófita \\
$\begin{array}{l}\text { Renealmia } \text { sp. } \\
\text { Indeterminada } 1\end{array}$ & Viana, J.L. et al. 361 & Heliófita & Caméfita \\
\hline
\end{tabular}

